Article

\title{
A Biomimetic Chitosan Derivates: Preparation, Characterization and Transdermal Enhancement Studies of $N$-Arginine Chitosan
}

\author{
Hui-Xia Lv ${ }^{1, \dagger}$, Zhen-Hai Zhang ${ }^{2, \dagger}$, Xiao-Pan Wang ${ }^{1}$, Qing-Qing Cheng ${ }^{1}$, Wei Wang ${ }^{1}$, \\ Xu-Hui Huang ${ }^{3, *}$, Jian-Ping Zhou ${ }^{1{ }^{*}}$, Qiang Zhang ${ }^{4}$, Lu-Lu Hou ${ }^{5}$ and Wei Huo ${ }^{5}$
}

1 Department of Pharmaceutics, China Pharmaceutical University, No. 24 tongjiaxiang Nanjing, China; E-Mail: lvhuixia@163.com (H.-X.L.)

2 Jiangsu Province Academy of Traditional Chinese Medicine, Nanjing, No. 100 shizhijie Nanjing, China; E-Mail: davidpharm@yeah.net

3 Department of Pharmacy, Fujian Provincial Hospital, China. No.134 dongjie Fuzhou, China

4 State Key Laboratory of Natural and Biomimetic Drugs, School of Pharmaceutical Sciences, Peking University, No.38 Xueyuan Road Haidian District, Beijing, China;

E-Mail: zhangqiangdodo@bjmu.edu.cn

5 Jiangxi Xierkangtai Pharmaceutical Co. Ltd., North Zone, High-New Technology Industrial Zone, Pingxiang, Jiangxi, China; E-Mail: hoululu_12345@hotmail.com (L.-L.H.)

$\dagger$ These authors contributed equally to this work.

* Authors to whom correspondence should be addressed; E-Mails: iamzhoujianping@163.com (J.-P.Z.); huangys1024@163.com (X.-H.H.); Tel.: +86 2583271102 (J.-P.Z.); Fax: +86-25-83301606 (J.-P.Z.); Tel.: +86-0591-87557768-2040(X.-H.H.).

Received: 11 July 2011; in revised form: 25 July 2011 / Accepted: 1 August 2011 /

Published: 9 August 2011

\begin{abstract}
A novel arginine-rich chitosan (CS) derivates mimicked cell penetration peptides; $N$-Arginine chitosan $(N$-Arg-CS) was prepared by two reaction methods involving activated L-arginine and the amine group on the chitosan. FTIR spectra showed that arginine was chemically coupled with CS. Elemental analysis estimated that the degrees of substitution (DS) of arginine in CS were 6\%,31.3\% and 61.5\%, respectively. The drug adefovir was chosen as model and its permeation flux across excised mice skin was investigated using a Franz diffusion cell. The results showed that the most effective enhancer was $2 \%(\mathrm{w} / \mathrm{v})$ concentration of $10 \mathrm{kDa} N$-Arg-CS with $6 \% \mathrm{DS}$. At neutral $\mathrm{pH}$, the
\end{abstract}


cumulative amount of adefovir permeated after 12 hours was $2.63 \pm 0.19 \mathrm{mg} \mathrm{cm}^{-2}$ which was 5.83-fold more than adefovir aqueous solution. Meanwhile $N$-Arg-CS was 1.83, 2.22, and 2.45 times more effective than Azone, eucalyptus and peppermint, respectively. The obtained results suggest that $N$-Arg-CS could be a promising transdermal enhancer.

Keywords: biomimetic chitosan derivates; arginine-rich; cell penetration peptides; $\mathrm{N}$-arginine chitosan; transdermal enhancer; adefovir

\section{Introduction}

Cell-penetrating peptides (CPPs) are short cationic peptides such as Transactivator of Transcription (TAT), penetratin and oligoarginine that facilitate the cellular uptake of various molecular cargos (from small chemical molecules to nanoparticles and large fragments of genes or proteins). CPPs typically have an amino acid-based composition that contains positively charged amino acids such as arginine or lysine. In the case of oligoarginine and related peptides, the salient structural feature is that they are very rich in arginin in general. There has been no real consensus as to the mechanism of CPP translocation, but there was no doubt that an arginine with a guanidinium group is critical to the translocation process [1,2]. Since arginine is abundant in cell-penetrating peptides which are highly cationic, they strongly adsorb on the membrane surfaces via hydrogen bond-induced formations of the guanidino moieties in arginine with anionic phosphates, sulfates, and carboxylates of cellular components [3].

Notably, chitosan (CS) is a nontoxic biopolymer that are produced by the deacetylation of chitin, and currently CS and its derivatives are receiving considerable attention in pharmaceutical and commercial applications due to their biological activities and properties [4-7]. Because of their permeation enhancing effect, enzyme inhibitory capabilities, mucoadhesive properties [8], CS and its derivatives are important excipients for delivery systems.

In this study, $N$-Arg-CSs, which we call biomimetic chitosan derivatives, prepared by chemical coupling of L-arginine, mimicked the argnine-rich peptides in order to get the cellular uptake functions of typical CPPs. $N$-ArgCSs were first reported in 2004 as novel anticoagulant biomaterials [9]. From then on some other functions of $\mathrm{N}$-Arg-CS were investigated. These functions include antibacterial action [10,11], gene transfection efficiency enhancement [12] and siRNA delivery [13]. Meanwhile our previous study (not published yet) has shown that $N$-Arg-CS can effectively enhance the oral absorption and the transdermal delivery of some drugs. To date, no report has ever describved the above function of $N$-Arg-CS.

Adefovir [9-(2-phosphonomethoxyethyl) adenine] is an acyclic nucleoside phosphonate used as a broad-spectrum antiviral that is highly effective against herpes-, retro-, and hepadnaviruses. Meanwhile other studies have shown that a $1-5 \mathrm{mg}$ dosage of adefovir is effective against filterable virus which causes skin disease [14]. The major drawbacks of adefovir with regard to oral administration are its low oral bioavailability, dose-dependent nephrotoxicity and gastrointestinal disturbance. Transdermal drug delivery offers numerous advantages over conventional routes of administration, by supplying a sustained release of drug to provide a steady plasma profile 
and hence reduce side effects, avoid the first-pass metabolism and circumvent the gastrointestinal tract. The aforementioned facts show that transdermal delivery of adefovir might be necessary as an alternative to the oral administration. Inspired by the aforementioned research work we have prepared a series of $\mathrm{N}$-Arg-CS with different molecular weights and DS values and explored their transdermal enhancement of adefovir absorption.

\section{Results and Discussion}

\subsection{Characterization of $N$-ArgCS samples}

The FTIR spectra of L-Arg, CS and N-Arg-CS-B samples are shown in Figure 1. For arginine, the absorption band at $1623.15 \mathrm{~cm}^{-1}$ is assigned to the guanido group, and the band at $1403 \mathrm{~cm}^{-1}$ is attributed to $\mathrm{COO}^{-}$symmetric bending. The $\mathrm{C}-\mathrm{C}-\mathrm{N}$ asymmetric bending and $\mathrm{COO}^{-}$scissioning modes are found at $1137 \mathrm{~cm}^{-1}$ and $773 \mathrm{~cm}^{-1}$, respectively [15,16]. Chitosan exhibits the characteristic bands of $\mathrm{NH}_{2}$ scissoring vibrations at $1669 \mathrm{~cm}^{-1}$, carbonyl asymmetric stretching vibrations at $1563 \mathrm{~cm}^{-1}$, and C-O stretching vibrations of the pyranose ring at $1068 \mathrm{~cm}^{-1}$ and $1010 \mathrm{~cm}^{-1}$ [17]. Comparing with those of chitosan and arginine, several noticeable changes are apparent in the spectra of $\mathrm{N}$-Arg-CS samples. The band of guanido group appears at $1615.97 \mathrm{~cm}^{-1}$ and the band of $\mathrm{C}-\mathrm{C}-\mathrm{N}$ asymmetric bending at $1149 \mathrm{~cm}^{-1}$. The new band at $1526.23 \mathrm{~cm}^{-1}$ is most likely due to an amide bond linking chitosan and arginine [9].

Figure 1. FTIR spectrums of the CS, L-Arg and $N$-Arg-CS-B.

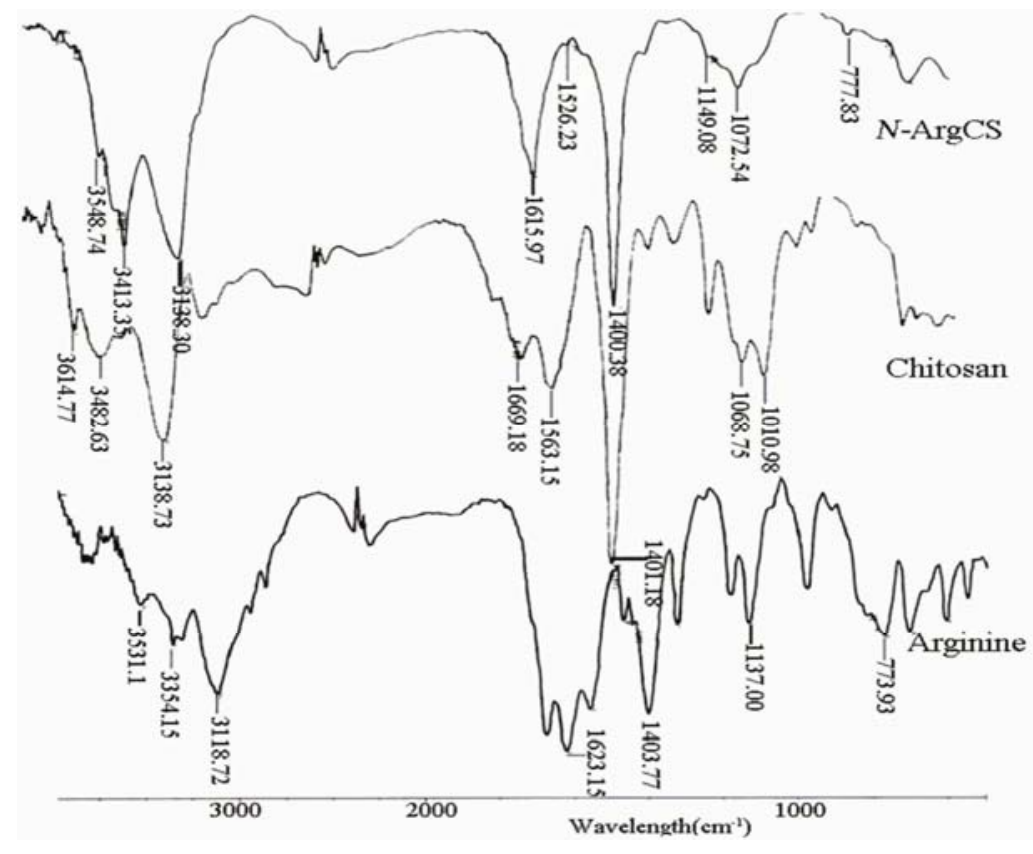

The substitution degrees of arginine in CS estimated from elemental analysis were about $6 \%$ ( $N$-Arg-CS-A, $N$-Arg-CS-B, and $N$-Arg-CS-C), 31.3\% ( $N$-Arg-CS-D) and 61.5\% ( $N$-Arg-CS-E), respectively, as presented in Table 1. 
Table 1. The elemental analysis of CS and $N$-Arg-CS.

\begin{tabular}{ccccccc}
\hline Samples & $\mathrm{MW}$ & $\mathrm{C}(\%)$ & $\mathrm{N}(\%)$ & $\mathrm{C} / \mathrm{N}$ & $\mathrm{DD}(\%)$ & $\mathrm{DS}(\%)$ \\
\hline $\mathrm{CS}$ & $10 \mathrm{kD}$ & $32.12 \pm 0.02$ & $6.06 \pm 0.05$ & 5.30 & 91.0 & - \\
$N$-ArgCS-A & $5 \mathrm{kD}$ & $36.68 \pm 0.01$ & $8.17 \pm 0.03$ & 4.49 & - & $6.3 \%$ \\
$N$-ArgCS-B & $10 \mathrm{kD}$ & $36.52 \pm 0.03$ & $8.08 \pm 0.05$ & 4.52 & - & $6.0 \%$ \\
$N$-ArgCS-C & $20 \mathrm{kD}$ & $36.56 \pm 0.06$ & $8.07 \pm 002$ & 4.53 & - & $5.9 \%$ \\
$N$-ArgCS-D & $10 \mathrm{kD}$ & $37.64 \pm 0.02$ & $12.26 \pm 0.08$ & 3.07 & - & $31.3 \%$ \\
$N$-ArgCS-E & $10 \mathrm{kD}$ & $48.95 \pm 0.04$ & $19.98 \pm 0.06$ & 2.45 & - & $61.5 \%$ \\
\hline
\end{tabular}

Notes: MW is molecular weight; DD is the degree of deacetylation; DS is the degree of substitution.

TG curves of chitosan and $N$-Arg-CS samples are shown in Figure 2. The thermogram of $N$-Arg-CS has three weight loss stages. The first stage ranges between 30 and $90{ }^{\circ} \mathrm{C}$ and shows about $11.15 \%$ loss in weight, corresponding to the evaporation of adsorbed and bound water. The second one starts at $90{ }^{\circ} \mathrm{C}$ and continues up to $180{ }^{\circ} \mathrm{C}$ during which there is no significant weight loss. The weight is abruptly decreased when the temperature reaches $250^{\circ} \mathrm{C}$ due to the degradation of $\mathrm{N}$-Arg-CS together with the breakage of the amide linkage of $N$-Arg-CS. Compared to $N$-Arg-CS, the first stage of chitosan decomposition occurs between 0 and $60{ }^{\circ} \mathrm{C}$, associated with the loss of bound water in the samples. The second one ranging from 60 to $300{ }^{\circ} \mathrm{C}$ corresponds to further dehydration and degradation of the samples.

Figure 2. TG thermogravimetric of CS and $N$-Arg-CS-B.

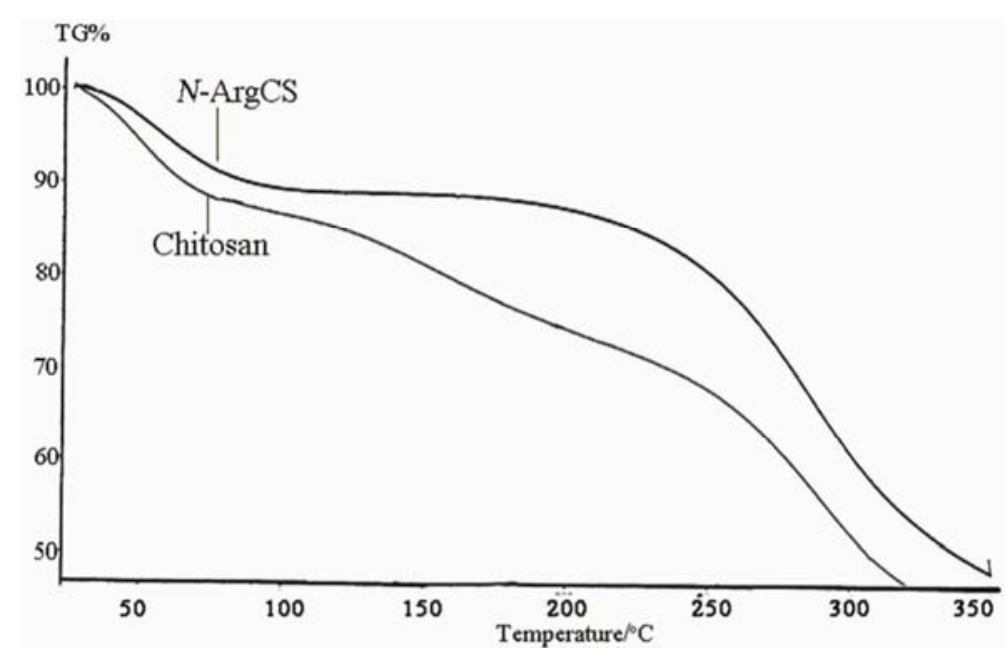

\subsection{In vitro skin permeation}

2.2.1. Skin penetration of Adefovir with $\mathrm{N}$-Arg-CS of different MWs in various $\mathrm{pH}$ values

Table 2 presents the accumulative percutaneous amount (Q) and steady-state permeation rate of adefovir with $60.0 \mathrm{mg} \mathrm{N}$-Arg-CS of different MWs in $3 \mathrm{~mL}$ adefovir solutions (containing $6.0 \mathrm{mg}$ of adefovir) at various $\mathrm{pH}$ values. 
Table 2. Effect of $\mathrm{N}$-Arg-CS at various $\mathrm{pH}$ values on the skin penetration of adefovir.

\begin{tabular}{cclc}
\hline Samples & $\mathbf{p H}$ & $\mathbf{Q n}\left(\boldsymbol{\mu g} \cdot \mathbf{c m}^{-\mathbf{2}}\right)$ & $\mathbf{J s s}\left(\boldsymbol{\mu} \mathbf{g} \cdot \mathbf{c m}^{-\mathbf{2}} \cdot \mathbf{h}^{\mathbf{- 1}}\right)$ \\
\hline & 3.0 & $457.08 \pm 17.15$ & 37.70 \\
Control & 5.0 & $457.69 \pm 21.00$ & 38.16 \\
& 7.0 & $450.82 \pm 23.02$ & 35.53 \\
& 9.0 & $330.65 \pm 24.38$ & 26.75 \\
\hline \multirow{3}{*}{$N$-Arg-CS-A } & 3.0 & $1714.07 \pm 7.79$ & 144.23 \\
& 5.0 & $1826.66 \pm 28.61$ & 148.61 \\
& 7.0 & $2125.53 \pm 118.48$ & 173.53 \\
$N$-Arg-CS-B & 9.0 & $1815.55 \pm 39.10$ & 149.32 \\
& 3.0 & $2306.56 \pm 23.61$ & 189.47 \\
& 7.0 & $2333.18 \pm 15.31$ & 191.60 \\
& 9.0 & $2628.86 \pm 71.50$ & 208.87 \\
$N$-Arg-CS-C & 3.0 & $2318.23 \pm 26.54$ & 191.35 \\
& 5.0 & $1386.08 \pm 33.82$ & 109.52 \\
& 7.0 & $2064.91 \pm 65.13$ & 110.69 \\
& 9.0 & $1861.52 \pm 24.11$ & 149.17 \\
\hline
\end{tabular}

The results showed that both transdermal permeation profile of adefovir with or without $N$-Arg-CS followed zero-order kinetics. Meanwhile, compared to those of adefovir solutions without enhancer, both the $\mathrm{Q}$ and $\mathrm{J}_{\mathrm{ss}}$ of adefovir solutions with $2 \% \mathrm{~N}$-Arg-CS-A, $\mathrm{N}$-Arg-CS-B, $N$-Arg-CS-C as enhancer, respectively, had significant difference $(\mathrm{P}<0.05)$. The effects of different $N$-Arg-CS specimens depended on the $\mathrm{pH}$. As for $N$-Arg-CS-A and $N$-Arg-CS-B, the cumulative percutaneous amount increased in the order $\mathrm{Q}_{\mathrm{pH} 3}<\mathrm{Q}_{\mathrm{pH} 5} \approx \mathrm{Q}_{\mathrm{pH} 9}<\mathrm{Q}_{\mathrm{pH} 7}$, and $\mathrm{Q}_{\mathrm{pH} 7}$ is higher than other three $\mathrm{Qs}(\mathrm{P}<0.05)$. However, the result of $N$-Arg-CS-C is a little different with the order $\mathrm{Q}_{\mathrm{pH} 3} \approx \mathrm{Q}_{\mathrm{pH} 5}<\mathrm{Q}_{\mathrm{pH} 9}<\mathrm{Q}_{\mathrm{pH} 7}$ and $\mathrm{Q}_{\mathrm{pH} 7}$ is also higher than other three Qs $(\mathrm{P}<0.05)$. This result supports the observation of Vávrova $[18,19]$.

The results obtained were likely due to different dissociation states of adefovir and $N$-Arg-CS in at the different $\mathrm{pH}$ values. Adefovir is an ionic compound with three $\mathrm{pK}_{\mathrm{a}} \mathrm{s}, 1.2$ (loss of a proton from the dihydrogenphosphonate and formation of a zwitterion), 4.2 (release of the free base at N1 and formation of a monoanion) and 6.8 (formation of a phosphonate dianion) [20]. At pH 7 adefovir exists in the form of a monoanion and a dianion with an almost equal 1:1 molar ratio. $\mathrm{N}$-Arg-CS is a positively charged polymer due to the existence of a different state of the guanido group of arginine in acidic, neutral and basic solutions. A complex of $N$-Arg-CS and adefovir might be formed by the interaction between positive and negative charge to enhance drug transdermal delivery.

Meanwhile different molecular weight $\mathrm{N}$-Arg-CS with the same DS had different accumulative percutaneous amounts. The results showed that the accumulative percutaneous amount with $N$-ArgCS-B (Mw, $10 \mathrm{kDa})$ was higher than that of $N$-Arg-CS-A (Mw, 5kDa) and $N$-Arg-CS-C (Mw, $20 \mathrm{kDa})$ under all $\mathrm{pH}$ circumstances.

\subsubsection{Effect of $N$-ArgCS DS and concentration on the skin penetration of adefovir}

The effect of $\mathrm{N}$-Arg-CS substitution value on adefovir transdermal delivery is presented in Figure 3(A). The results showed that the cumulative percutaneous amount with $N$-Arg-CS-B was significantly 
higher than that of $N$-Arg-CS-D and $N$-Arg-CS-E $(\mathrm{P}<0.05)$. Meanwhile, there is no significant difference between $N$-Arg-CS-D and $N$-Arg-CS-E (P > 0.05). It was unexpected that the increase in DS of the $N$-Arg-CSs did not enhance their penetration properties.

Figure 3. Effect of $N$-Arg-CS with different substitution values (A) and concentrations (B) on the skin penetration of adefovir after $12 \mathrm{~h}(\mathrm{n}=6)(\mathrm{A}$ : The samples are $N$-Arg-CS-B, $N$-Arg-CS-D and $N$-Arg-CS-E and the concentration is $2 \%$; B: The sample is $N$-Arg-CS-B).
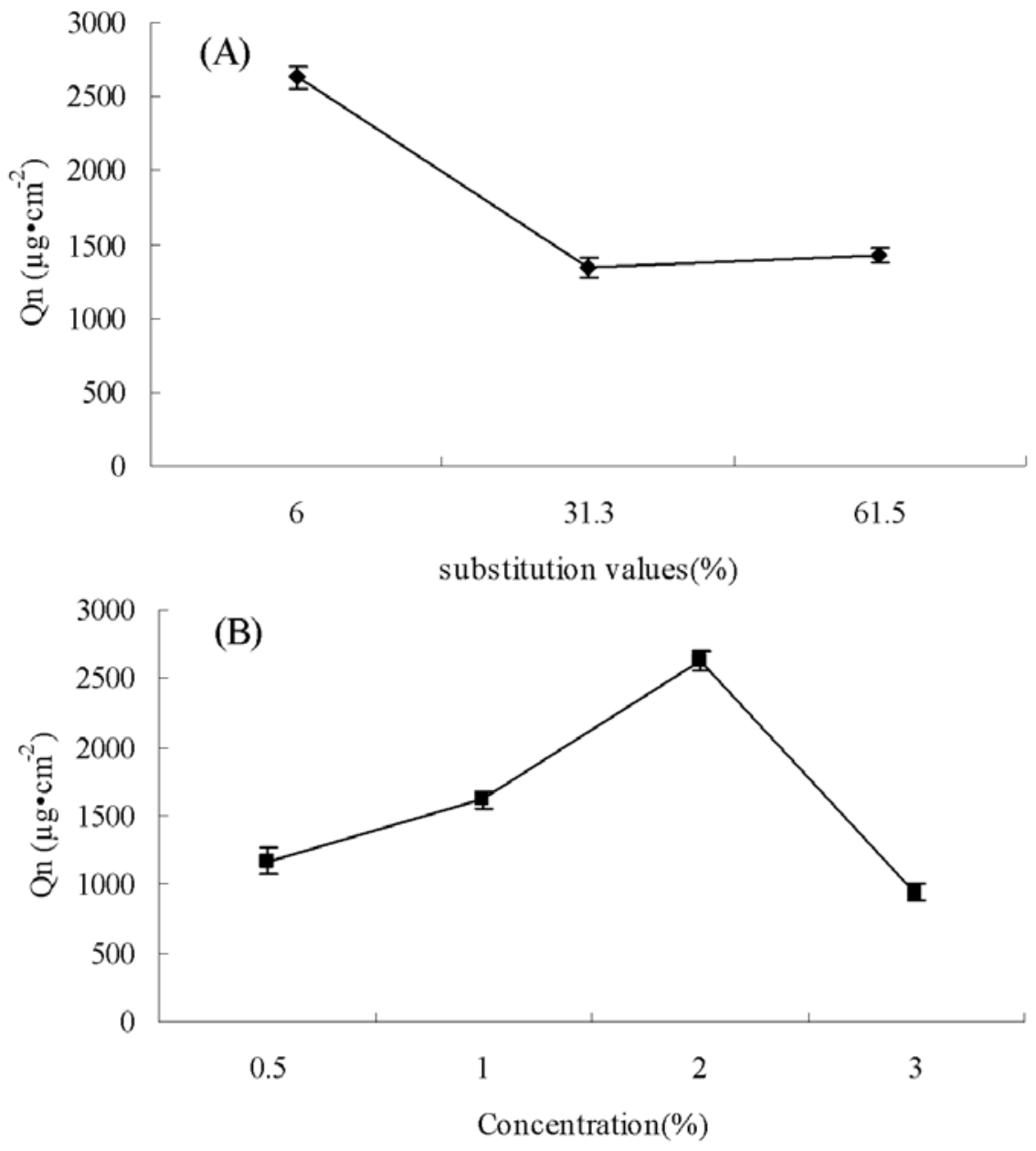

Regarding the use of different concentrations of $N$-Arg-CS, the situation is the same as in the case of DS. The increase in concentration of $\mathrm{N}$-Arg-CS did not lead to an increase in the penetration enhancement properties of $\mathrm{N}$-Arg-CS as presented in Figure 3(B). $2 \%$ of $\mathrm{N}$-Arg-CS seemed to be the optimum concentration.

\subsubsection{Comparison of different enhancers}

Table 3 and Figure 4 present the accumulative percutaneous amount (Q) of adefovir with $60 \mathrm{mg}$ arginine, different MW chitosans, physical mixtures of arginine and chitosan (1:1) and N-Arg-CS in $3 \mathrm{~mL}$ natural $\mathrm{pH}$ adefovir solution (contains $6.0 \mathrm{mg}$ of adefovir). 
Table 3. The accumulated transportation of adefovir across mice skins with various enhancers after $12 \mathrm{~h}(\mathrm{n}=6)$.

\begin{tabular}{ccc}
\hline Enhancer & $\mathbf{Q n} / \mathbf{\mu g} \cdot \mathbf{c m}$ & $\mathbf{J s s} / \mathbf{\mu g} \cdot \mathbf{c m}^{\mathbf{- 2}} \cdot \mathbf{h}^{\mathbf{- 1}}$ \\
\hline Control & $450.82 \pm 23.02$ & 35.53 \\
L-Arg & $701.16 \pm 27.99$ & 60.13 \\
CS5000 & $652.41 \pm 29.65$ & 51.83 \\
CS10000 & $729.82 \pm 35.45$ & 55.08 \\
CS20000 & $660.89 \pm 21.02$ & 59.13 \\
Mixture of CS5000\& L-Arg & $975.12 \pm 47.37$ & 79.13 \\
Mixture of CS10000\& L-Arg & $1097.58 \pm 49.88$ & 93.30 \\
Mixture of CS20000\& L-Arg & $819.91 \pm 26.08$ & 64.02 \\
$N$-Arg-CS-A & $2125.53 \pm 118.48$ & 173.53 \\
$N$-Arg-CS-B & $2628.86 \pm 71.50$ & 208.87 \\
$N$-Arg-CS-C & $2064.91 \pm 65.13$ & 169.17 \\
Azone & $1439.04 \pm 59.51$ & 124.59 \\
Eucalyptus & $1182.55 \pm 76.43$ & 98.47 \\
Peppermint & $1072.81 \pm 55.82$ & 73.51 \\
\hline
\end{tabular}

Figure 4. The accumulated transportation of adefovir across mice skins with various enhancers after $12 \mathrm{~h}(\mathrm{n}=6)$.

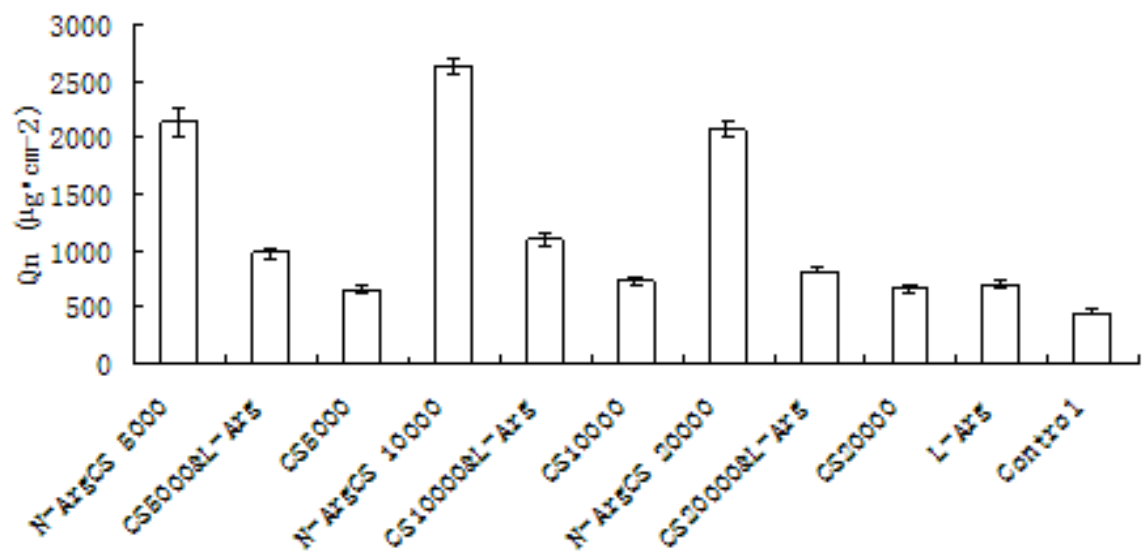

The results show that the cumulative amount of adefovir with arginine, different MWs CS and the physical mixture of arginine and CS after 12 hour were 1.53, 1.43, 1.60, 1.44, 2.13, 2.40, 1.79 folds more than control sample, respectively. The transdermal enhancement of the arginine is likely due to its guanidino group. It was reported that guanidino group had the ability to open the tight junctions between cells and to reduce the membrane potential [21]; the chitosan can open the tight junctions of the epithelia [8]. The enhancement of arginine and CS mixture could be of the addition effect of both materials. Furthermore the cumulative amount of adefovir with $\mathrm{N}$-Arg-CS-A, B, C after 12 hours was $4.71,5.83,4.58$ times that of the control, respectively The above shows that $N$-Arg-CS, chemical coupling of arginine and CS could be an promising transdermal enhancer for adefovir.

Azone (1-dodecylazacyclohepta $N$-2-one or laurocapram) was the first molecular that was specifically designed as a skin penetration enhancer. It probably exerts its penetration enhancing effects through the interactions with the lipid domains of the stratum corneum. Eucalyptus and 
peppermint are essential oils, and they can impact membrane fluidity to exert their penetration enhancement [22]. Comparison of $N$-Arg-CS enhancement with that provided by azone, eucalyptus and peppermint is presented in Table 3 and Figure 5. The results show that cumulative amount drug permeated by azone, eucalyptus and peppermint after 12 hours was 2.14, 1.58, 1.34-fold more than control, respectively. The enhancement of $N$-Arg-CS-B was found to be 1.83, 2.22, 2.45 folds more than that of azone, eucalyptus and peppermint, respectively. These results show that $N$-Arg-CS is slightly superior to typical penetration enhancers.

Figure 5. The accumulated transportation of adefovir across mice skins with various enhancers after $12 \mathrm{~h}(\mathrm{n}=6)$.

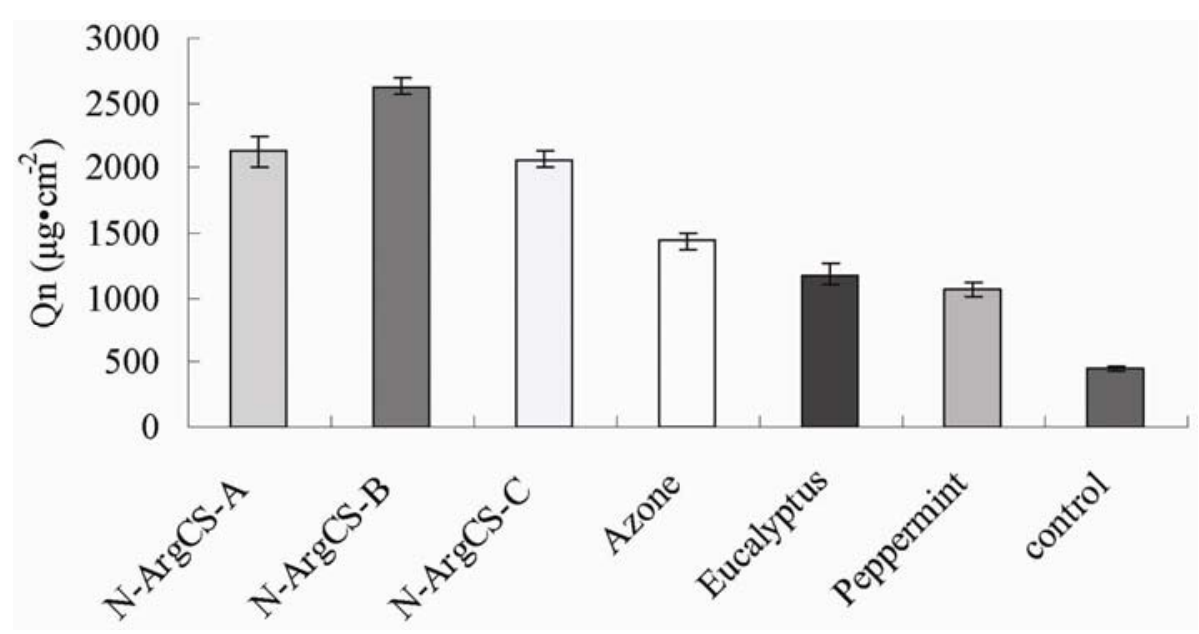

\section{Experimental}

\subsection{Materials}

CS (MW5 kDa, $10 \mathrm{kDa}, 20 \mathrm{kD}$, DD > 90\%) from shrimp was purchased from Golde $N$-shell Biochemical Co., Ltd. (Zhejiang, China). L-Arg was purchased from Shanghai HuiXing Biochemistry Reagent Limited Company. (Shanghai, China). Adefovir was purchased from Nanjing Chia-Tai Tianqing Pharmacy Co. Ltd. (Nanjing, China). All the other chemicals were of analytical grade and can be used without further purification. Healthy male Kunming species mice (25-30 g) were supplied by Qinglongshan Laboratory Animal Center. (Nanjing, China). All animal experiments complied with the rules that are set forth in the NHI Guide of the Care and Use of Laboratory Animals.

\subsection{Synthesis of $N$-ArgCS with different $D S$}

\subsubsection{Synthesis of $N$-ArgCS with low DS}

The $N$-ArgCS samples with low DS were synthesized by a modified method described elsewhere [9], as shown in the Scheme 1(1). First L-Arg (0.3 g) was dissolved in distilled water (10 mL). $N$-hydroxysuccinimide (NHS) and 1-ethyl-3-(3-dimethylaminopropyl) carbodiimide (EDC) were added to the solution, respectively, at a fixed molar ratio of $1: 1: 3$, to activate the carboxyl group of L-Arg. The $\mathrm{pH}$ of the resultant solution was adjusted to 6 with $1 \%$ acetic acid and $1 \% \mathrm{NaOH}$ solution. The carboxyl group of L-Arg was activated for $2 \mathrm{~h}$. Secondly; chitosan ( $1 \mathrm{~g}, \mathrm{MW} 5 \mathrm{kDa}$ ) was dissolved in 1\% acetic 
acid solution $(100 \mathrm{~mL})$. The $\mathrm{pH}$ was adjusted in the same manner as L-Arg solution with $1 \% \mathrm{NaOH}$ solution. The activated L-Arg solution was added to the chitosan solution to react at ambient temperature with continuous stirring for $48 \mathrm{~h}$. The resultant solution was dialyzed (MWCO =3,500) against distilled water for $48 \mathrm{~h}$, then lyophilized. The final product was named as $N$-ArgCS-A. Using the same method for preparation of $N$-ArgCS-A, and other chitosans (MW $10 \mathrm{kDa}$ and $20 \mathrm{kDa}$ ) $\mathrm{N}$ ArgCS-B and $N$-ArgCS-C, were produced, respectively.

Scheme 1. Two methods of $N$-ArgCS synthesis.

(1)

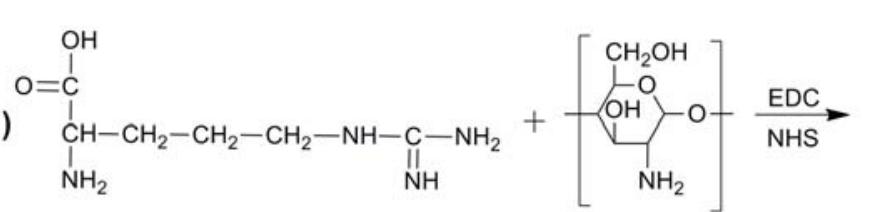

L-Arginine

(2) Step i

$$
\begin{aligned}
& \text { L-Arginine }
\end{aligned}
$$

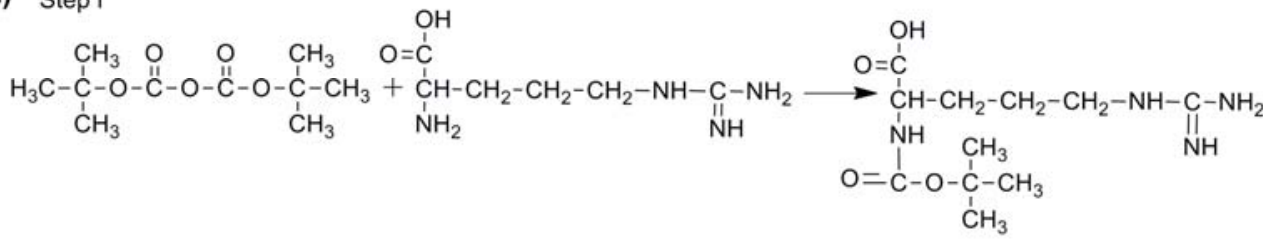

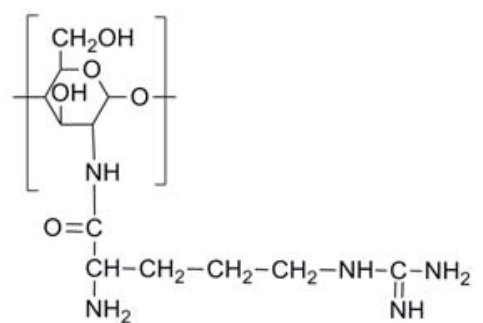

N-ArgCS

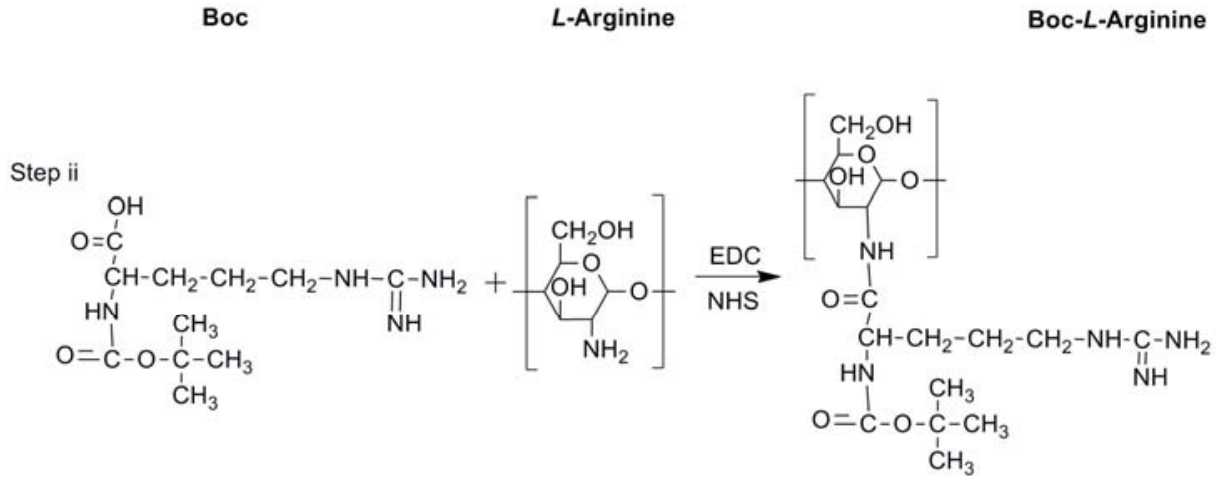

$$
\text { Boc-L-Arginine }
$$

chitosan

Boc-L-Arginine chitosan

Step iii

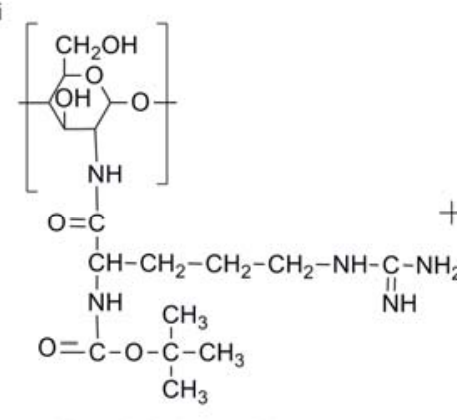

Boc-L-Arginine chitosan

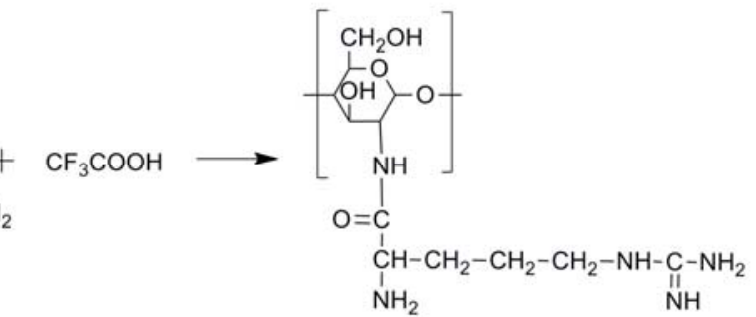

N-ArgCS

\subsubsection{Synthesis of $N$-ArgCS with high DS}

In order to increase the DS, dicarbonic acid bis (1,1-dimethylethyl)ester (Boc 20) was used to prevent the reaction of activated L-Arg molecules with each other, as shown in Scheme 1(2). L-Arg 
$(0.44 \mathrm{~g})$ was dissolved in distilled water $(20 \mathrm{~mL})$. Boc $(0.54 \mathrm{~g})$ was dissolved in tetrahydrofuran (THF, $20 \mathrm{~mL}$ ), and then added to the L-Arg solution. The $\mathrm{pH}$ was adjusted to 6 with $1 \mathrm{M} \mathrm{NaOH}$ solution and allowed to react at ambient temperature for $24 \mathrm{~h}$. The product was isolated by removing the THF under reduced pressure using a rotary evaporator. The final product from the evaporation process was dissolved again in distilled water $(20 \mathrm{~mL})$. NHS and EDC were added at fixed molar ratio of 1:1:3 $(\mathrm{g} / \mathrm{g} / \mathrm{g})$ as L-Arg/NHS/EDC, respectively. The $\mathrm{pH}$ of the resultant solution was adjusted to 6 with $1 \%$ acetic acid and $1 \% \mathrm{NaOH}$ solution. The Boc carboxyl group of the protected L-Arg was activated for $2 \mathrm{~h}$. Exactly $1 \mathrm{~g}$ of chitosan (MW $10 \mathrm{kDa}$ ) was dissolved in $1 \%$ acetic acid solution $(100 \mathrm{~mL})$ and the $\mathrm{pH}$ was adjusted to 6 . The activated Boc protected L-Arg solution was added into chitosan solution to react at ambient temperature with continuous stirring for $48 \mathrm{~h}$. After the reaction was complete, the Boc groups were deprotected with $1 \% \mathrm{CF}_{3} \mathrm{COOH}$. The obtained solution was dialyzed ( $\mathrm{MW}$ cutoff $=3,500$ ) against distilled water for $48 \mathrm{~h}$ and then lyophilized. The final product was named as $N$-Arg-CS-D. $N$-ArgCS-E was prepared in the same manner with the ratio of 1:1.31:1.63 (g/g/g, CS/L-Arg /Boc).

\subsection{Characterization of $N$-ArgCS}

FTIR spectra of chitosan, L-Arg and $N$-ArgCS-B were measured by using a FT-IT Nicolet Impact 410 spectrophotometer. Powder samples were mixed with $\mathrm{KBr}$, and pressed into disks for measurement. The DS of $N$-Arg-CS sample was determined by elemental analysis $(\mathrm{C}, \mathrm{N})$ using a Vario EL III elemental analysis instrument. Thermal degradation (TG) of samples was monitored using a thermal analyzer. Chitosan and $N$-ArgCS-B were heated from ambient temperature to $400{ }^{\circ} \mathrm{C}$ at a constant heating rate of $10 \% \mathrm{~min}$ under a nitrogen atmosphere.

\subsection{In vitro permeation experiments}

Abdominal skins were obtained from male Kunming species mice weighing 25-30 g. After its hair was shaved carefully with an electric clipper, the skin was excised from the abdominal region of each scarified mouse and the subcutaneous fat and other extraneous tissues were trimmed out with physiologic saline. The excised mice skins were washed, then stored at 4 and used within $12 \mathrm{~h}$ after the skin was harvested. The permeation experiments were performed using Franz diffusion cells fitted with excised mice skins at $32{ }^{\circ} \mathrm{C}$. The effective diffusion area was $1.54 \mathrm{~cm}^{-2}$ and the receptor chamber was filled with $16 \mathrm{~mL}$ of physiologic saline which was constantly stirred at $400 \mathrm{rpm}$ throughout the experiment. After adefovir and $\mathrm{N}$-Arg-CS mixture solution was applied on the epidermal surface of the skin, $2 \mathrm{~mL}$ of medium in receptor chamber was withdrawn at specific time intervals for up to $12 \mathrm{~h}$. An equal volume of the fresh physiologic saline was immediately replenished after each sampling process. Collected samples were filtered through $0.22 \mu \mathrm{m}$ microporous membrane filter and adefovir was quantified by HPLC analysis.

\subsection{Drug analysis}

Samples were analyzed by LC - 10AT VP HPLC system with a SPD - 10A VP variable-wavelength ultraviolet absorbance detector and a reverse phase Licrosphere $C_{18}$ column $(250 \mathrm{~mm} \times 4.6 \mathrm{~mm} \mathrm{i.} \mathrm{d}, 5 \mu \mathrm{m})$ operating at room temperature. The sample $(1 \mathrm{~mL})$ was precipitated by $1 \mathrm{~mL}$ methanol and filtered by 
using $0.22 \mu \mathrm{m}$ filter membrane. The mobile phase composed of a mixture of methanol/phosphate buffer at $\mathrm{pH} 2.5$ in a ratio of $80: 20 \mathrm{v} / \mathrm{v}$, respectively, the flow rate was $0.5 \mathrm{~mL} \cdot \mathrm{min}^{-1}$. Adefovir was detected at $261 \mathrm{~nm}$ with the retention time of $5.3 \mathrm{~min}$. The standard curve was linear over the concentration range $1-90 \mu \mathrm{g} \cdot \mathrm{mL}^{-1}\left(\mathrm{R}^{2}=0.9999\right)$. The coefficients of variation (RSD) for inter- and intraday variation was both below $1 \%$.

\subsection{Data analysis}

The cumulative amount of adefovir permeating through the skin was plotted as a function of time. The skin flux was determined from Fick's law of diffusion: $\mathrm{J}_{\mathrm{ss}}=\mathrm{dQ}_{\mathrm{n}} /$ Adt. Where, $\mathrm{J}_{\mathrm{ss}}$ is the steady-state skin flux in $\mu \mathrm{g} \cdot \mathrm{cm}^{-2} \cdot \mathrm{h}^{-1}, \mathrm{dQ}_{\mathrm{n}}$ is change in quantity of the drug passing through the skin into the receptor chamber in $\mathrm{dt}$ hours, $\mathrm{A}$ is the active diffusion area in $\mathrm{cm}^{2}$ and $\mathrm{dt}$ is the change in time [23]. The cumulative amount of drug permeating through the skin at different time intervals was calculated by equation (1):

$$
Q n=\frac{C n \times V o+\sum_{i=1}^{n-1} C i \times V}{A}
$$

where $\mathrm{Cn}$ is the drug concentration of the receiver solution at each sampling time, $\mathrm{Ci}$ the drug concentration of the $\mathrm{i}(\mathrm{h})$ sample, and $\mathrm{V}_{0}$ and $\mathrm{V}$ the volumes of the receiver solution and the sample, respectively, A represents the skin surface area. The flux was calculated from the slope of the linear portion of the profile. All parameters were reported as the mean \pm S.D. Statistical analysis was carried out by using analysis of variance (ANOVA). The level of significant was taken as $\mathrm{P}<0.05$. A correlation analysis was performed with the aid of the SPSS program, and correlation co-efficient were examined for significance $(\mathrm{P}<0.05)$ by using Student's t-test.

\section{Conclusions}

In summary, the above experimental results show that different molecular weights of $\mathrm{N}$-Arg-CS with different degrees of substitution have the potential to enhance the rate of adefovir transdermal delivery. In particular, the most effective transdermal enhancer is $2 \%(2 \mathrm{mg} / \mathrm{mL}) \mathrm{N}$-Arg-CS (MW $10 \mathrm{kDa}$ ) with $6 \%$ substitution degree. Chemically a complex of arginine and CS can significantly enhance the transdermal penetration compared to arginine and CS used singly, which was considered to be a result of strong interaction between positive and negative charge in $N$-Arg-CS and adefovir, then the guanidinium groups and amino groups of $N$-Arg-CS are strongly adsorbed on the cell membrane surfaces to open the tight junctions of the epithelia, allowing for the paracellular transport. These $N$-Arg-CS simulated arginine-rich cell penetration peptides have potential as a novel transdermal enhancer, although the mechanism of action needs further investigation.

\section{Acknowledgments}

The National Natural Science Foundation of China (No. 30901867 and No. 30973649) is gratefully acknowledged for financial support. This work was also supported by the National Basic Research Program of China (973 Program, No. 2009CB903300). 


\section{Conflict of Interest}

The authors declare no conflict of interest.

\section{References}

1. Trehin, R.; Merkle, H.P. Chances and Pitfalls of Cell Penetrating Peptides for Cellular Drug Delivery. Eur. J. Pharm. Biopharm. 2004, 58, 209-223.

2. Surendra, N.; Ramesh, C. Guanidinium-grafted polyethylenimine: An efficient transfecting agent for mammalian cells. Eur. J. Pharm. Biopharm. 2008, 68, 647-655.

3. Fuchs, S.M.; Raines, R.T. Pathway for polyarginine entry into mammalian cells. Biochemisty 2004, 9, 2438-2444.

4. Kumar, M.N.V.R. A review of chitin and chitosan applications. React. Funct. Polym. 2000, 46, $1-27$.

5. Yoshifumi, M.; Youko, K.; Daijirou, H.; Kyouko, K.; Susumu, K. Properties of an Oral Preparation Containing a Chitosan Salt. Molecules 2009, 14, 755-762.

6. Tajik, H.; Moradi, M.; Rohani, S.M.R.; Erfani, A.M.; Jalali, F.S.S. Preparation of Chitosan from Brine Shrimp (Artemia urmiana) Cyst Shells and Effects of Different Chemical Processing Sequences on the Physicochemical and Functional Properties of the Product. Molecules 2008, 13, 1263-1274.

7. Asadinezhad, A.; Novák, I.; Lehocký, M.; Bílek, F.; Vesel, A.; Junkar, I.; Sáha, P.; Popelka, A. Polysaccharides Coatings on Medical-Grade PVC: A Probe into Surface Characteristics and the Extent of Bacterial Adhesion. Molecules 2010, 15, 1007-1027.

8. Borchard, G.; Lueßen, H.L.; de Boer, A.G.; Verhoe, J.C.; Lehrc, C.-M.; Junginger, H.E. The potential of mucoadhesive polymers in enhancing intestinal peptide drug absorption III: Effects of chitosan-glutamate and carbomer on epithelial tight junctions in vitro. J. Control. Rel. 1996, 39, 131-136.

9. Liu, W.G.; Zhang, J.R.; Cao, Z.Q.; Xu, F.Y.; Yao, K.D. A chitosan-arginine conjugate as a novel anticoagulation biomaterial. J. Mater. Sci. Mater. Med. 2004, 15, 1199-1203.

10. Tang, H.; Zhang, P.; Kieft, T.L; Ryan, S.J.; Baker, S.M.; Wiesmann, W.P.; Rogelj, S. Antibacterial action of a novel functionalized chitosan-arginine against Gram-negative bacteria. Acta Biomater. 2010, 6, 2562-2571.

11. Xiao, B.; Wan, Y.; Zhao, M.Q; Liu, Y.Q.; Zhang, S.M. Preparation and characterization of antimicrobial chitosan- $N$-arginine with different degrees of substitution. Carbohydr. Polym. 2011, 83, 144-150.

12. Mansouri, S.; Lavigne, P.; Corsi, K.; Benderdour, M.; Beaumont, E.; Fernandes, J.C. ChitosanDNA nanoparticles as non-viral vectors in gene therapy: strategies to improve transfection efficacy. Eur. J. Pharm. Biopharm. 2004, 57, 1-8.

13. Noh, S.M.; Park, M.O.; Shim, G.; Han, S.E.; Lee, H.Y.; Huh, J.H.; Kim, M.S.; Choi, J.J.; Kim, K.; Kwon I.C. Pegylated poly-1-arginine derivatives of chitosan for effective delivery of siRNA. J. Control. Release 2010, 145, 159-164. 
14. Holy, A. Phosphonomethoxyalkyl analogs of nucleotides. Curr. Pharm. Des. 2010, 39, 2567-2592.

15. Pal, T.; Kar, T. Single crystal growth and characterization of the nonlinear optical crystal L-arginine hydrofluoride. J. Cryst. Growth. 2002, 234, 267-271.

16. Xu, D.; Wang, X.Q.; Yu, W.T.; Xu, S.X.; Zhang, G.H. Crystal structure and characterization of a novel organic nonlinear optical crystal: L-arginine trifluoroacetate. J. Cryst. Growth. 2003, 253, 481-487.

17. Banerjee, T.; Mitra, S.; Kumar Singh, A.; Sharma, R.K.; Maitra, A. Preparation, characterization and biodistribution of ultrafine chitosan nanoparticles. Int. J. Pharm. 2002, 243, 93-105.

18. Vavrova, K.; Lorencova, K.; Klimentova, J.; Novotny, J.; Holy, A.N.; Hrabalek, A. Transdermal and dermal delivery of adefovir: effects of $\mathrm{pH}$ and permeation enhancers. Eur. J. Pharm. Biopharm. 2008a, 69, 597-604.

19. Vavrova, K.; Lorencova, K.; Novotny, J.; Holy, A.; Hrabalek, A. Permeation enhancer dodecyl 6-(dimethylamino)hexanoate increases transdermal and topical delivery of adefovir: influence of pH, ion-pairing and skin species. Eur. J. Pharm. Biopharm. 2008b, 70, 901-907.

20. Kopecky, V.; Mojzes, P., Jr.; Burda, J.V.; Dostal, L. Raman spectroscopy study of acid-base and structural properties of 9-[2-(phosphonomethoxy)ethyl]adenine in aqueous solutions. Biopolymers 2002, 67, 285-288.

21. Kosuge, M.; Takeuchi, T.; Nakase, I.; Jones, A.T.; Futaki, S. Cellular internalization and distribution of arginine-rich peptides as a function of extracellular peptide concentration, serum, and plasma membrane associated proteoglycans. Bioconjug. Chem. 2008, 19, 656-664.

22. Williams, A.C.; Barry, B.W. Penetration enhancers. Adv. Drug. Deliv. Rev. 2004, 56, 603-618.

23. Zhao, L.; Fang, L.; Xu, Y.; Zhao, Y.; He, Z. Effect of O-acylmenthol on transdermal delivery of drugs with different lipophilicity. Int. J. Pharm. 2008, 352, 92-103.

Sample Availability: Contact the authors.

(C) 2011 by the authors; licensee MDPI, Basel, Switzerland. This article is an open access article distributed under the terms and conditions of the Creative Commons Attribution license (http://creativecommons.org/licenses/by/3.0/). 